\title{
POPULATION STUDY ARTICLE Deliberate self-harm among children with disabilities in China: a matched case-control study
}

\author{
Qi Gao ${ }^{1}$, Henry Xiang ${ }^{2}$, Yu-Tao Xiang ${ }^{3}$ and Huiping Zhu ${ }^{1}$
}

\begin{abstract}
BACKGROUND: Study about deliberate self-harm (DSH) in children with different types of disabilities was scarce. This study compared the incidence and patterns of DSH between children with and without disabilities aged 6-17 years using a matched case-control study in Beijing.

METHODS: A total of 650 pairs of children with and without disabilities were surveyed. Characteristics of latest episode of self-harm within the 12 months were compared. Associations between disability status, sociodemographic factors, smoking, drinking, sleep problems, and self-harm were examined.

RESULTS: Children with disabilities showed significant higher incidence of DSH than children without disabilities. Two groups differed significantly in terms of self-harm methods, body parts injured, premeditation, wishing to be known by others and helpseeking behavior. The adjusted OR for self-harm was 4.76 (2.99-7.55) for children with disabilities compared with children without disabilities. Children who slept fewer than $6 \mathrm{~h}$ per night, had difficulty falling asleep at night sometimes/often, and went to sleep after midnight 1 to 3 nights per month or at least once a week were at elevated risk of self-harm.

CONCLUSION: This study highlights a strong relationship between disability, sleep problems, and DSH. Interventions to reduce selfharm should target disability and sleep problems as important risk factors.
\end{abstract}

Pediatric Research (2019) 85:275-282; https://doi.org/10.1038/s41390-018-0258-7

\section{INTRODUCTION}

Deliberate self-harm (DSH) is a widespread problem in children and adolescents around the world. Results from a seven-country comparative community study of DSH among over 30,000, mainly 15 - and 16 -year-old children, found that $8.9 \%$ of females and $2.6 \%$ of males reported an episode of self-harm in the past year. ${ }^{1}$ Nonfatal self-harm frequently leads to repetition (16\% after 1 year and $23 \%$ after 4 years), and it is often recognized as a precursor to completed suicide. ${ }^{2}$ It is estimated that around a quarter of suicides might be preceded by non-fatal self-harm in the previous year. ${ }^{3}$ Thus, self-harm is highlighted in national suicide prevention strategy in many countries like UK, Australia, Belgium, and Norway. ${ }^{1,4}$

Globally, it is estimated that $10 \%$ of children ( 200 million) live with some kind of disability. ${ }^{5}$ They are thought to be at significantly greater risk of violence and injury than their counterparts without disabilities. ${ }^{6-8}$ For children with disabilities, previous studies mostly focused on self-harm among those with intellectual disability (ID) and autism spectrum disorder (ASD). ${ }^{9-11}$ So far, most of the self-harm literature have only focused on children with certain kind of disability, and studies about repeated self-harm in children with a wide range of disabilities were lacking. As self-harm could be associated with significant subsequent morbidity and is the key risk factor for future suicide, there is an urgent need to predict self-harm and its repetition. ${ }^{12}$

In China, over 5 million children younger than 17 years old has a disability. ${ }^{13}$ Data from several regional cross-sectional studies reported that prevalence of self-harm has ranged from $7.2 \%$ to $35.6 \%$ among Chinese children. ${ }^{14,15}$ To date, however, epidemiological study about this problem in Chinese children with disabilities was scarce, and self-harm had never been compared directly between children with and without disabilities. Improved information is needed to obtain accurate estimates of self-harm incidence in children with disabilities so as to recognize the urgency and scope of this problem and allocate health resources and services. The present study aims to examine the incidence of self-harm occurred during the previous 12 months among children with different types of disabilities, and to describe the characteristics and risk factors of self-harm within this vulnerable Chinese pediatric population by using a 1:1 matched case-control study.

\section{METHODS}

Participants

This study was conducted in Beijing, the capital of the People's Republic of China. The sampling frame of all local special education schools was provided by Beijing Municipal Education Commission. There were 22 special education schools in 16 urban and suburban districts of Beijing, and 11 of them were randomly selected using a computer program. The selected schools were informed of the project through invitation letters, and all schools agreed to participate in our study. All children with disabilities aged 6-17 years in the 11 special education schools were recruited into the study. According to the selected special schools, we chose the general education schools which were nearest to the special schools in the same district, and the basic information of children like age, gender, and family address in these schools was

\footnotetext{
${ }^{1}$ Department of Epidemiology and Health Statistics, School of Public Health, Capital Medical University, Beijing, China; ${ }^{2}$ The Research Institute at Nationwide Children's Hospital, The Ohio State University College of Medicine, Columbus, OH, USA and ${ }^{3}$ Unit of Psychiatry, Faculty of Health Sciences, University of Macau, Macao SAR, China Correspondence: Huiping Zhu (zhuhuiping@ccmu.edu.cn)
} 
collected. For every child with disabilities, we matched a child without disabilities (same age and gender, and lived in the same district) who was randomly recruited from these general education schools.

Our study was approved by the Institutional Review Board of Capital Medical University. Informed consent form was obtained in writing from a parent of each child before the day of survey.

\section{Disability classification}

Children with disabilities attending the special education schools in Beijing were registered in China Disabled Persons' Federation (CDPF). CDPF is the official agency for individuals with disability in China, which issued an official certificate to define the type and severity of disability for each person with disability. In this study, we classified disability using the following five groups defined by the China Classification and Grading Criteria of Disability: mental retardation, hearing disability, speech disability, physical disabilities, and mental health disorders. , $16,17^{\text {Type of disability was }}$ recorded in the questionnaire by children and their parents, which was in accord with the disability type listed in the official certificates for children with disabilities.

Health and behavior questionnaire

We developed a questionnaire that included questions regarding basic demographic features, smoking, drinking, sleep patterns, health and lifestyle, disabling condition, suicide behavior, and selfharm behavior. Data on sleep patterns were assessed using questions from our previous publication and studies conducted by United States researchers. ${ }^{18,19}$ We focused on the details about the most recent episode of self-harm that occurred during the previous 12 months (date, method, whether the act was premeditated or impulsive, medical treatment after self-harm, use of alcohol or drugs at time of episode, etc.). Premeditation was classified according to the time interval (from "less than $30 \mathrm{~min}^{\text {" to }}$ "a week or more") between starting to think about harming themselves and carrying it out. Occasional DSH was defined as a frequency of 1 to 4 times, and repetitive DSH was defined as the frequency of 5 times or more during the past year.

The questionnaire was first piloted in a small group of children in two of the selected schools. Questionnaire was finalized using feedback from the pilot study. In the present study, disabling condition was viewed as a risk factor for DSH, thus, in order to ensure that the child's disability presented before the act of selfharm occurred, a child must have the disabling condition(s) for at least 12 months prior to the survey.

\section{Procedure}

All fieldwork began in September 2017 and finished in February 2018. The questionnaire was administered in classrooms by the school teachers and researcher staff within $30 \mathrm{~min}$ in all participating schools. Consenting parents completed the questionnaire for young children (6-10 years), and for children (11-17 years) who were unable to fill out the questionnaire by themselves. Children aged 11-17 years who were capable of filling out the questionnaire for themselves completed questionnaire on their own and anonymously. Parents and children were assured of the total confidentiality and anonymity. To avoid possible bias, children and their parents were instructed to avoid discussions during the survey.

\section{Definition of DSH}

Strict standard was developed to classify DSH events depending on the response to the following key question: "Have(s) you (your child) deliberately tried to harm yourself (him/herself) in the last year in one or more of the following types (24 self-harm options provided, such as taking overdoses, cutting yourself)?" and the response option could be "no"', "yes, "once", "yes, 2-4 acts of selfharm", and "yes, $\geq 5$ acts of self-harm".
DSH was defined as a non-fatal act in which an individual did one or more of the following behaviors deliberately. ${ }^{1}$

- Self-initiated behavior (such as self-cutting, -burning, -banging, etc.).

- Ingestion of a substance in excess of the prescribed therapeutic dose.

- Ingestion of a substance or object non-ingestible.

In this study, children met the criteria for self-harm if it included one of the acts outlined above, and had occurred at least once. We did not judge according to their motives for self-harm, but that the act appeared deliberately, since determination of a child's intent during self-harm could not reliably be performed, especially for a child too young, or a child with mental health disorders, or mental retardation in the present study.

Statistical analyses

All analyses were performed using SAS statistical software. We first compared the incidence of DSH between children with and without disabilities by sociodemographic, sleep, smoking, and drinking factors. Chi-square tests were used to assess the association between self-harm status and disability status by these variables. Then we compared the characteristics of self-harm episodes between the two groups of children. Finally, all of the variables mentioned above were included in the multivariate analysis, and logistic regression model was used to assess the risk of self-harm in sampled children.

\section{RESULTS}

A total of 738 children with disabilities were eligible for inclusion in our study, of which 672 agreed, resulting in a participation rate of $91.1 \%$. Finally, 650 children with disabilities were present at the day of survey and completed the questionnaire. Also, 650 children without disabilities were included in our study. Overall, $62.5 \%$ of the sample was male and $37.5 \%$ were female in both of the groups. The median age of the sampled children was 12.0 (IQR: 9.0-14.0) years.

As presented in Table 1, children with disabilities had a substantially higher incidence of DSH than children without disabilities ( 20.6 vs. $10.9 \%, P<0.001)$. The rates of self-harm differed significantly between the two groups with respect to variables such as gender, ethnic group, whether being a single child or not, family income per month, and smoking.

The age-of-onset of DSH varied significantly between children with and without disabilities $(P<0.001)$. The median age-of-onset of self-harm was 8.0 (IQR: 6.0-11.0) years for children with disabilities, compared with 12.0 (IQR: 10.0-14.0) years for children without disabilities.

Characteristics of self-harm episodes among sampled children with and without disabilities are presented in Table 2. Two groups differed significantly in terms of self-harm methods, body parts injured, premeditation, whether somebody else knew, anybody else had self-harm, wishing to be known by others, and helpseeking behavior after self-harm. Although multiple methods remained the most common method of DSH among both of the groups, using another single method (such as self-scratching, -carving, -burning, -hitting, hanging, jumping, or overdose) and self-biting were more likely to be reported among children with disabilities than children without disabilities. Upper extremities were the most common body parts injured reported by both groups, but injuries to the head/neck region were more common for children with disabilities (37.6 vs. $8.5 \%$ ). Almost $80.0 \%$ of children with disabilities, but $60.6 \%$ of children without disabilities decided to harm themselves within $30 \mathrm{~min}$ of doing so.

Table 3 presents the sampled children classified into three groups (no, occasional, and repetitive DSH) based on the reported 
Table 1. Incidence of DSH among children with and without disabilities, by sociodemographic, smoking, drinking, and sleeprelated factors in Beijing, China

\begin{tabular}{|c|c|c|c|c|c|}
\hline \multirow[t]{2}{*}{ Characteristics } & \multicolumn{2}{|c|}{$\begin{array}{l}\text { Children without } \\
\text { disability }\end{array}$} & \multicolumn{2}{|c|}{$\begin{array}{l}\text { Children with } \\
\text { disability }\end{array}$} & \multirow[t]{2}{*}{$P$-value } \\
\hline & $N$ & Injured $n(\%)$ & $N$ & Injured $n(\%)$ & \\
\hline Total & 650 & $71(10.9)$ & 650 & $134(20.6)$ & $<0.001$ \\
\hline \multicolumn{6}{|l|}{ Gender } \\
\hline Male & 406 & $51(12.6)$ & 406 & $84(20.7)$ & 0.003 \\
\hline Female & 244 & $20(8.2)$ & 244 & $50(20.5)$ & $<0.001$ \\
\hline \multicolumn{6}{|l|}{ Age (year) } \\
\hline $6-9$ & 184 & $4(2.2)$ & 184 & $42(22.8)$ & $<0.001$ \\
\hline $10-13$ & 283 & $20(7.1)$ & 283 & $50(17.7)$ & $<0.001$ \\
\hline $14-17$ & 183 & $47(25.7)$ & 183 & $42(23.0)$ & 0.626 \\
\hline \multicolumn{6}{|l|}{ Ethnic group } \\
\hline Han Chinese & 617 & $67(10.9)$ & 601 & $116(19.3)$ & $<0.001$ \\
\hline Ethnic minorities & 33 & $4(12.1)$ & 49 & $18(36.7)$ & 0.027 \\
\hline \multicolumn{6}{|c|}{ Parent-child relationship } \\
\hline Natural parents & 628 & $66(10.51)$ & 609 & $124(20.36)$ & $<0.001$ \\
\hline $\begin{array}{l}\text { Adoptive parents/ } \\
\text { step-parents }\end{array}$ & 22 & $5(22.73)$ & 41 & $10(24.39)$ & 0.883 \\
\hline \multicolumn{6}{|l|}{ Single parent } \\
\hline Yes & 42 & $9(21.4)$ & 78 & $16(20.5)$ & 1.000 \\
\hline No & 608 & $62(10.2)$ & 572 & $118(20.6)$ & 0.000 \\
\hline \multicolumn{6}{|l|}{ Single child } \\
\hline Yes & 514 & $55(10.7)$ & 370 & $75(20.3)$ & 0.000 \\
\hline No & 136 & $16(11.8)$ & 280 & $59(21.1)$ & 0.029 \\
\hline \multicolumn{6}{|l|}{ Father's education } \\
\hline $\begin{array}{l}\text { Middle school or } \\
\text { less }\end{array}$ & 64 & $12(18.8)$ & 177 & $31(17.5)$ & 0.975 \\
\hline High school & 202 & $29(14.4)$ & 187 & $30(16.0)$ & 0.748 \\
\hline $\begin{array}{l}\text { Undergraduate } \\
\text { degree or higher }\end{array}$ & 384 & $30(7.8)$ & 286 & $73(25.5)$ & 0.000 \\
\hline \multicolumn{6}{|l|}{ Mother's education } \\
\hline $\begin{array}{l}\text { Middle school or } \\
\text { less }\end{array}$ & 67 & $12(17.9)$ & 187 & $32(17.1)$ & 1.000 \\
\hline High school & 178 & $22(12.4)$ & 195 & $30(15.4)$ & 0.488 \\
\hline $\begin{array}{l}\text { Undergraduate } \\
\text { degree or higher }\end{array}$ & 405 & $37(9.1)$ & 268 & $72(26.9)$ & 0.000 \\
\hline \multicolumn{6}{|c|}{ Family income per month } \\
\hline$<5000$ & 99 & $8(8.1)$ & 273 & $50(18.3)$ & 0.025 \\
\hline $5000-12,000$ & 372 & $46(12.4)$ & 254 & $49(19.3)$ & 0.024 \\
\hline$>12,000$ & 179 & $17(9.5)$ & 123 & $35(28.5)$ & $<0.001$ \\
\hline \multicolumn{6}{|l|}{ Smoking } \\
\hline Yes & 26 & $13(50.0)$ & 15 & $2(13.3)$ & 0.044 \\
\hline No & 624 & $58(9.3)$ & 635 & $132(20.8)$ & 0.000 \\
\hline \multicolumn{6}{|l|}{ Drinking } \\
\hline Yes & 153 & $43(28.1)$ & 46 & $12(26.1)$ & 0.936 \\
\hline No & 497 & $28(5.6)$ & 604 & $122(20.2)$ & 0.000 \\
\hline \multicolumn{6}{|c|}{ Average hours of sleep per night } \\
\hline$<6$ & 76 & $27(35.53)$ & 10 & $5(50.00)$ & 0.588 \\
\hline $6-8$ & 291 & $37(12.71)$ & 152 & $36(23.68)$ & 0.005 \\
\hline$>8$ & 283 & $7(2.47)$ & 488 & $93(19.06)$ & 0.000 \\
\hline \multicolumn{6}{|c|}{ Having difficulty falling asleep at night } \\
\hline Never/rarely & 421 & $26(6.18)$ & 384 & $52(13.54)$ & 0.001 \\
\hline Sometimes & 182 & $31(17.03)$ & 195 & $47(24.10)$ & 0.117 \\
\hline
\end{tabular}

Table 1. continued

\begin{tabular}{|c|c|c|c|c|c|}
\hline \multirow[t]{2}{*}{ Characteristics } & \multicolumn{2}{|c|}{$\begin{array}{l}\text { Children without } \\
\text { disability }\end{array}$} & \multicolumn{2}{|c|}{$\begin{array}{l}\text { Children with } \\
\text { disability }\end{array}$} & \multirow[t]{2}{*}{$P$-value } \\
\hline & $N$ & Injured $n(\%)$ & $N$ & Injured $n(\%)$ & \\
\hline Often & 47 & $14(29.79)$ & 71 & $35(49.30)$ & 0.056 \\
\hline \multicolumn{6}{|l|}{ Using sleeping pills } \\
\hline Never/rarely & 643 & $68(10.58)$ & 624 & $128(20.51)$ & 0.000 \\
\hline Sometimes/often & 7 & $3(42.86)$ & 26 & $6(23.08)$ & 0.572 \\
\hline \multicolumn{6}{|c|}{ Going to sleep after midnight } \\
\hline Never/rarely & 381 & $12(3.15)$ & 568 & $104(18.31)$ & 0.000 \\
\hline $\begin{array}{l}1 \text { to } 3 \text { nights per } \\
\text { month }\end{array}$ & 137 & $18(13.14)$ & 54 & $18(33.33)$ & 0.003 \\
\hline $\begin{array}{l}\text { At least once a } \\
\text { week }\end{array}$ & 132 & $41(31.06)$ & 28 & $12(42.86)$ & 0.325 \\
\hline
\end{tabular}

history of DSH. The rates of occasional and repetitive DSH were 4.2 and $11.5 \%$, respectively. Disability status, smoking, drinking, average hours of sleep per night, having difficulty falling asleep at night, and going to sleep after midnight were significantly associated with repetitive DSH. Children with disabilities had substantially higher rate of repetitive DSH than children without disabilities (15.2 vs. $7.9 \%, P<0.001$ ).

Table 4 presents the ORs for DSH by disability status, sociodemographic, smoking, drinking, and sleep-related factors. In univariate analysis, the OR for self-harm was $2.12(95 \%$ $\mathrm{Cl}: 1.55-2.89)$ for children with disabilities compared with children without disabilities. Children aged 14 to 17 years from ethnic minorities, smoking, drinking, sleeping fewer than $6 \mathrm{~h}$ a night, having difficulty falling asleep at night sometimes/often, and going to sleep after midnight 1 to 3 nights per month or at least once a week had an increased risk of self-harm. The adjusted OR of self-harm among children with disabilities was significantly higher than that among children without disabilities $(O R=4.76$; $95 \% \mathrm{Cl}=2.99,7.55 ; P<0.01)$. Children who reported ethnic minorities, drinking, sleeping fewer than $6 \mathrm{~h}$ per night, having difficulty falling asleep at night sometimes/often, and going to sleep after midnight 1 to 3 nights per month or at least once a week were at elevated risk of self-harm after controlling for potential confounders.

\section{DISCUSSION}

Our study was possibly the first study that investigated risk of selfharm among children with a wide range of disabilities in China. This study provided important preliminary evidence for elevated risk and characteristics of self-harm in children with disabilities.

In this study, overall incidence of DSH during the previous 12 months among the sampled children was $15.8 \%$. Studies from England and Australia reported that about 6 to $7 \%$ of children aged 15 years had DSH in the previous year, ${ }^{20,21}$ which is lower than the incidence rate in our study. In addition, our results showed $4.2 \%$ children reported occasional $\mathrm{DSH}$, and $11.5 \%$ reported repetitive DSH. A study from Germany showed $10.9 \%$ of the school students reported the occasional form of DSH within the previous year, and $4.0 \%$ reported the repetitive form of $\mathrm{DSH}^{22}$ Diverse rates of self-harm within studies might be explained by the different study samples, sociocultural context, definition of self-harm including occasional and repetitive forms, measuring the presence of self-harm in prior years or lifetime, type of school, and age range of study participants.

Our study examined DSH in a special vulnerable pediatric population and showed children with disabilities had significantly higher incidence of DSH than children without disabilities 
Table 2. Characteristics of DSH in sampled Chinese children with and without disability, Beijing, China

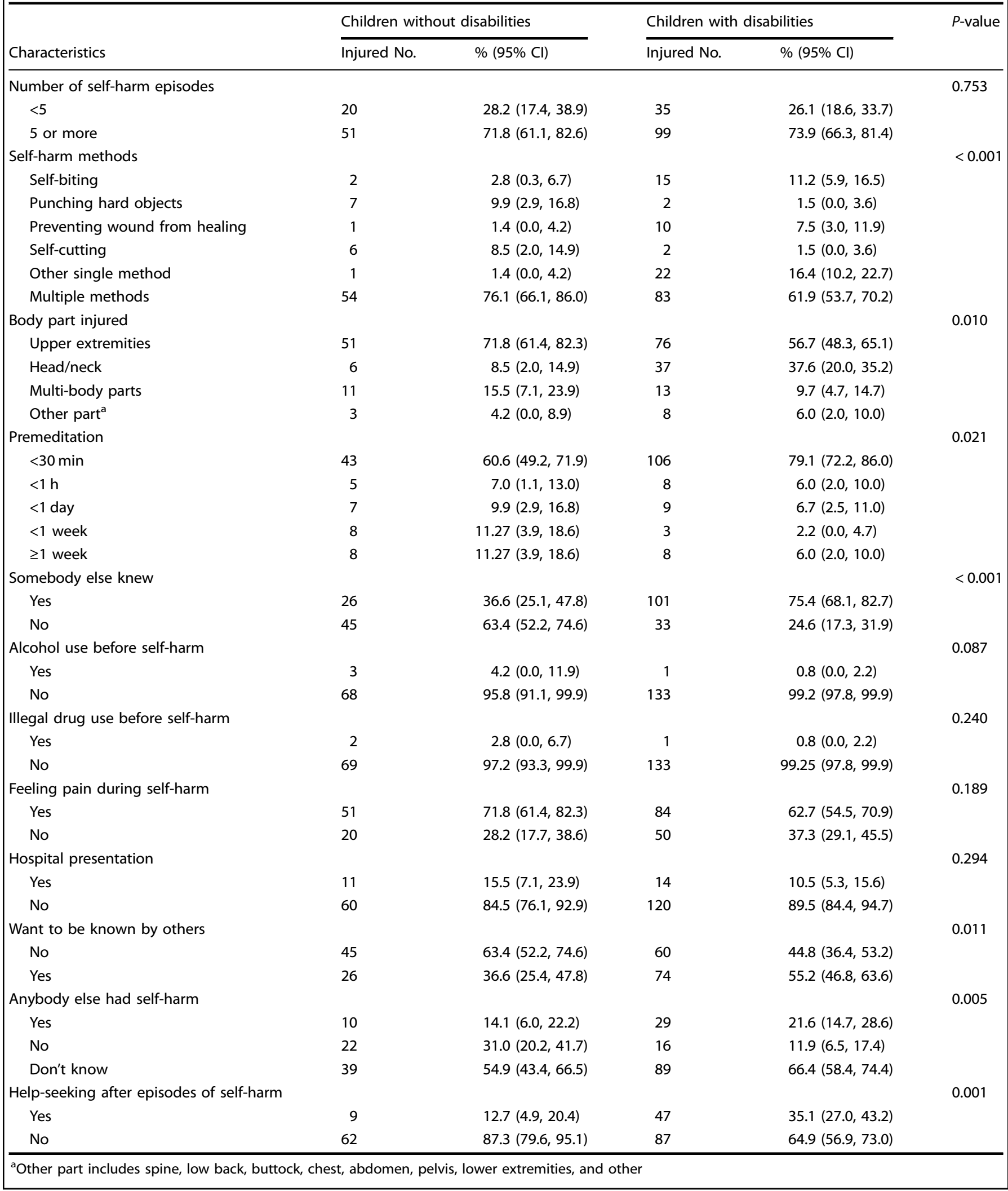

(20.6 vs. 10.9\%). Previous studies indicated that psychiatric conditions such as borderline personality disorder are associated with $\mathrm{DSH}$, and self-harm has a high prevalence rate among children with ID and ASD..$^{9,10,23,24}$ A previous study of
943 children with severe ID reported $17.0 \%$ of the sampled children showed self-harm. ${ }^{25}$ For children with ASD, the prevalence rate is even higher, occurring in around $50 \%$ of this population. ${ }^{9,10,23}$ 
Deliberate self-harm among children with disabilities in China: a matched... Q Gao et al.

Table 3. Distribution of DSH in the sampled Chinese children by sociodemographic, sleep, smoking, and drinking characteristics

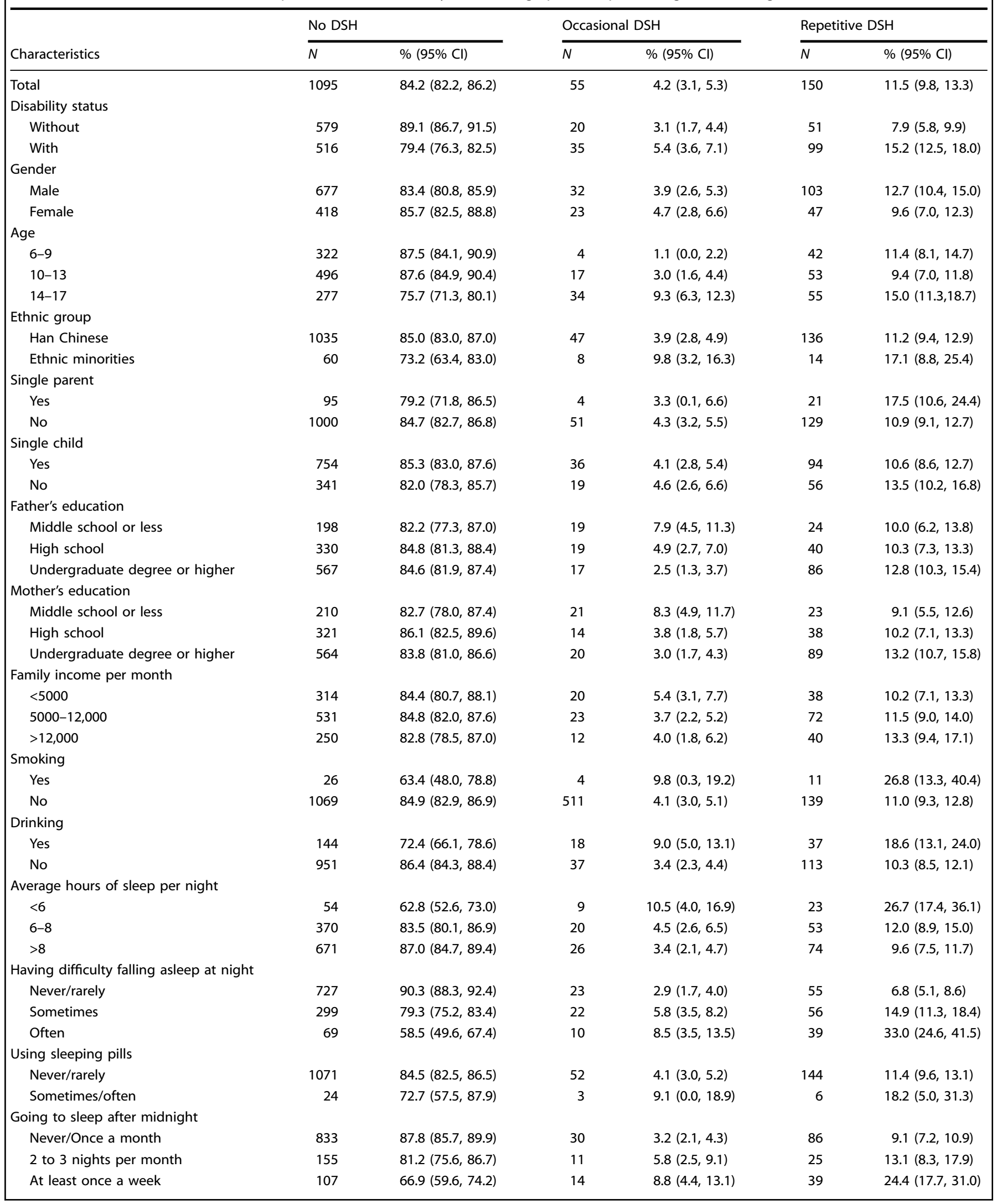


Table 4. Logistic regression analysis of DSH by disability status, sociodemographic, smoking, drinking, and sleep factors

\begin{tabular}{|c|c|c|}
\hline Variables & $\begin{array}{l}\text { Univariate model } \\
\text { OR } 95 \% \mathrm{Cl}\end{array}$ & $\begin{array}{l}\text { Multivariate model } \\
\text { OR } 95 \% \mathrm{Cl}\end{array}$ \\
\hline \multicolumn{3}{|l|}{ Disability status } \\
\hline Without & 1 & 1 \\
\hline With & $2.12(1.55,2.89)^{*}$ & $4.76(2.99,7.55)^{* *}$ \\
\hline \multicolumn{3}{|l|}{ Gender } \\
\hline Male & 1 & 1 \\
\hline Female & $0.84(0.61,1.15)$ & $0.96(0.68,1.35)$ \\
\hline \multicolumn{3}{|l|}{ Age } \\
\hline $6-9$ & 1 & 1 \\
\hline $10-13$ & $0.99(0.66,1.47)$ & $0.73(0.46,1.15)$ \\
\hline $14-17$ & $2.25(1.52,3.32)^{*}$ & $1.01(0.61,1.67)$ \\
\hline \multicolumn{3}{|l|}{ Ethnic group } \\
\hline Han Chinese & 1 & 1 \\
\hline Ethnic minorities & $2.07(1.24,3.46)^{*}$ & $1.92(1.07,3.45)^{*}$ \\
\hline \multicolumn{3}{|l|}{ Parent-child relationship } \\
\hline Natural parents & 1 & 1 \\
\hline $\begin{array}{l}\text { Adoptive parents/ } \\
\text { stepparents }\end{array}$ & $1.72(0.95,3.14)$ & $1.74(0.89,3.40)$ \\
\hline \multicolumn{3}{|l|}{ Single parent } \\
\hline Yes & 1 & 1 \\
\hline No & $0.68(0.43,1.09)$ & $0.86(0.51,1.47)$ \\
\hline \multicolumn{3}{|l|}{ Single child } \\
\hline Yes & 1 & 1 \\
\hline No & $1.28(0.93,1.74)$ & $1.10(0.76,1.58)$ \\
\hline \multicolumn{3}{|l|}{ Father's education } \\
\hline Middle school or less & 1 & 1 \\
\hline High school & $0.82(0.54,1.27)$ & $0.67(0.38,1.18)$ \\
\hline $\begin{array}{l}\text { Undergraduate degree or } \\
\text { higher }\end{array}$ & $0.84(0.57,1.24)$ & $0.67(0.35,1.31)$ \\
\hline \multicolumn{3}{|l|}{ Mother's education } \\
\hline Middle school or less & 1 & 1 \\
\hline High school & $0.77(0.50,1.20)$ & $1.09(0.61,1.95)$ \\
\hline $\begin{array}{l}\text { Undergraduate degree or } \\
\text { higher }\end{array}$ & $0.92(0.63,1.36)$ & $1.61(0.82,3.15)$ \\
\hline \multicolumn{3}{|l|}{ Family income per month } \\
\hline$<5000$ & 1 & 1 \\
\hline $5000-12000$ & $0.97(0.68,1.38)$ & $1.25(0.82,1.92)$ \\
\hline$>12000$ & $1.13(0.75,1.70)$ & $1.39(0.82,2.35)$ \\
\hline \multicolumn{3}{|l|}{ Smoking } \\
\hline Yes & 1 & 1 \\
\hline No & $0.31(0.16,0.59)^{*}$ & $0.64(0.29,1.39)$ \\
\hline \multicolumn{3}{|l|}{ Drinking } \\
\hline Yes & 1 & 1 \\
\hline No & $0.41(0.29,0.59)^{*}$ & $0.48(0.29,0.77)^{* *}$ \\
\hline \multicolumn{3}{|c|}{ Average hours of sleep per night } \\
\hline$<6$ & 1 & 1 \\
\hline $6-8$ & $0.33(0.20,0.55)^{*}$ & $0.45(0.24,0.84)^{*}$ \\
\hline$>8$ & $0.25(0.16,0.41)^{*}$ & $0.36(0.18,0.71)^{* *}$ \\
\hline \multicolumn{3}{|c|}{ Having difficulty falling asleep at night } \\
\hline Never/rarely & 1 & 1 \\
\hline Sometimes & $2.43(1.73,3.42)^{*}$ & $1.95(1.35,2.84)^{* *}$ \\
\hline Often & $3.62(2.29,7.22)^{*}$ & $4.74(2.91,7.71)^{* *}$ \\
\hline Using sleeping pills & & \\
\hline
\end{tabular}

\begin{tabular}{|lll|}
\hline Table 4. continued & & \\
\hline Variables & $\begin{array}{l}\text { Univariate model } \\
\text { OR } 95 \% \mathrm{Cl}\end{array}$ & $\begin{array}{l}\text { Multivariate model } \\
\text { OR } 95 \% \mathrm{Cl}\end{array}$ \\
\hline $\begin{array}{lll}\text { Never/rarely } \\
\text { Sometimes/often }\end{array}$ & 1 & 1 \\
Going to sleep after midnight & $2.05(0.94,4.48)$ & $0.96(0.39,2.34)$ \\
$\quad$ Never/Once a month & 1 & 1 \\
1 to 3 nights per month & $1.67(1.11,2.52)^{*}$ & $1.75(1.04,2.97)^{*}$ \\
At least once a week & $3.56(2.43,5.21)^{*}$ & $2.79(1.57,4.93)^{* *}$ \\
\hline${ }^{*} P<0.05,{ }^{* *} P<0.01$ & & \\
\hline
\end{tabular}

Repetitive is a key component of self-harm. ${ }^{24}$ We found children with disabilities had significantly higher incidence of repetitive DSH than children without disabilities (15.2 vs. 7.9\%). Disability status, smoking, drinking, and sleep problems were positively linked to repetitive DSH. These findings are consistent with earlier reports. Previous studies found that the majority of self-injurers in psychiatric samples had engaged in the behavior much more frequently (average of $>50$ episodes in the past year), while most general adolescents who engage in self-injury reported doing so only a few times ( $<10$ lifetime episodes). ${ }^{26-28}$ Also, our findings are consistent with previous studies showing that the risk factors associating with self-harm in adolescents included alcohol use, smoking, and sleep problems. ${ }^{9,22,29-31}$ Rossow et al. ${ }^{32}$ reported the risk of DSH was higher among adolescents who used alcohol. Brunner et al. ${ }^{22}$ found that adolescent girls who smoked demonstrated an elevated risk for both occasional and repetitive DSH.

Sleep plays an essential role in our overall health. ${ }^{33}$ In 2015, the National Sleep Foundation (NSF) updated sleep duration recommendations that suggest the appropriate sleep duration for school-aged children (6-13 years) is between $9 \mathrm{~h}$ and $11 \mathrm{~h}$, and for teenagers (14-17 years) between $8 \mathrm{~h}$ and $10 \mathrm{~h}^{34}$ Thus, according to the recommended sleep time durations, $8 \mathrm{~h}$ of sleep and longer may be appropriate for children in our study. However, we found that only $43.5 \%$ children without disabilities and $75.1 \%$ children with disabilities slept more than $8 \mathrm{~h}$, and $11.7 \%$ children without disabilities slept less than $6 \mathrm{~h}$ a night, which is not recommended by NSF. Individuals with sleep durations far outside the normal range may have serious health problems, and there has been growing evidence that sleep disturbances are important factors for risk of self-harm and suicide. $^{29-31,33}$ Consistent with findings from previous studies, we found a strong association between sleep problems and DSH as insufficient sleep duration $(<6 \mathrm{~h})$, having difficulty falling asleep at night sometimes/often, and going to sleep after midnight 1 to 3 nights per month or at least once a week yielded higher odds of selfharm. Our results underline the importance of healthy sleep in the prevention of self-harm for children.

The most commonly used method of self-harm reported by the general population across studies was self-cutting or self-carving, with most common body parts injured occurring on the arms. ${ }^{1,6,26,35}$ In our study, we also found upper extremities were the most self-injured parts reported by both groups of children. However, the majority of children in the two groups reported using multiple methods of self-harm, using another single method and self-biting were more likely to be reported by children with disabilities, and punching hard objects and self-cutting were more frequent among children without disabilities. Children with and without disabilities differed significantly with respect to self-harm methods, and this result was similar to the finding from a study that self-harm among people with developmental disabilities is a completely different phenomenon compared with that occurring among normally developing people because of the differences in forms of self-harm. ${ }^{27}$ 
Nock et al. ${ }^{36}$ revealed that when self-harm presents thoughts of engaging in self-injury, which typically ( $85 \%$ of the time) lasts less than $1 \mathrm{~h}$. Findings of our study also indicated that $85.1 \%$ of children with disabilities and $67.6 \%$ of children without disabilities decided to harm themselves within an hour of starting thought about self-harm. Our results showed over $28.0 \%$ children without disabilities and $37.0 \%$ children with disabilities reported feeling no pain during episodes of self-harm. This finding is consistent with results from previous studies that many self-injurers report feeling little or no pain when engaging in this behavior. ${ }^{26,37}$

Results of this study suggested that children with disabilities were even younger when they inflicted DSH for the first time (the median age-of-onset 8.0 years vs. 12 years). These findings support previous findings that self-harm typically begins between 10 and 14 years, $^{38}$ and self-harm is correlated with a younger age in children with disability. ${ }^{22}$

A limitation of our study is that the rates in these analyses may underestimate the true incidence of DSH as parents of children having a history of DSH might be less willing to participate in the study, and self-harmers might have more school absence days than those students who did not have self-harm or may be less likely to respond to questionnaires on self-harm. Also, the incidence of DSH may be underestimated by parental bias. Previous studies reported the discrepancy between children's reports and parents' proxy reports on emotional and behavioral problems of children. ${ }^{39,40}$ Second, our study was based on retrospective reporting from parents or children themselves, and was thus subject to recall bias. Our results would be biased if respondents for children with disabilities reported self-harm differently than respondents for children without disabilities. Further research is needed to identify how disability status influences recall bias in self-harm reporting by respondents. Third, we could not establish causality between these risk factors and DSH since the nature of this study design. Last, we did not take into account the potential influence of school (general and special school) environment, which might have impact on our results.

Despite these limitations, our findings contribute to the limited knowledge concerning the incidence, form, and risk factors of selfharm in children with disabilities in China. Our study is important as it has implications for DSH prevention targeting this vulnerable population. We found DSH is prevalent in Chinese children, and children with disabilities had a substantially higher incidence of DSH than children without disabilities. Interventions to prevent self-harm should be an important public health priority for children with disabilities in China.

\section{ACKNOWLEDGEMENTS}

The authors thank all study participants and school teachers from all participating schools, particularly Guangyu Sun, Xiaolin Xie, Jie Zhang, Yanpeng Zhao, and Yan Cao.

\section{FUNDING}

This study was funded by Beijing Natural Science Foundation (Grant No. 7172026).

\section{AUTHOR CONTRIBUTIONS}

H.Z. and H.X. conceived and designed the study. Q.G. and H.Z. performed the study. Q.G. and Y.-T.X. analyzed the data. H.Z. and Q.G. wrote the paper. H.X. and Y.-T.X. revised the paper.

\section{ADDITIONAL INFORMATION}

Competing interests: The authors declare no competing interests.

Publisher's note: Springer Nature remains neutral with regard to jurisdictional claims in published maps and institutional affiliations.

\section{REFERENCES}

1. Madge, N. et al. Deliberate self-harm within an international community sample of young people: comparative findings from the Child \& Adolescent Self-harm in Europe (CASE) Study. J. Child Psychol. Psychiatry 49, 667-677 (2008).

2. Owens, D., Horrocks, J. \& House, A. Fatal and non-fatal repetition of self-harm. Syst. Rev. Br. J. Psychiatry 181, 193-199 (2002).

3. Owens, D. \& House, A. General hospital services for deliberate self-harm. Haphazard clinical provision, little research, no central strategy. J. R. Coll. Physicians Lond. 28, 370-371 (1994).

4. Department of Health. National suicide prevention strategy for England. (Department of Health, London, 2002).

5. Halfon, N., Houtrow, A., Larson, K. \& Newacheck, P. W. The changing landscape of disability in childhood. Future Child. 22, 13-42 (2012).

6. United Nations. The state of the world's children 2013: children with disabilities. (UNICEF, New York, 2013).

7. Sinclair, S. \& Xiang, H. Injuries among US children with different types of disabilities. Am. J. Public Health 98, 1510-1516 (2008).

8. Zhu, H. et al. Unintentional injuries among Chinese children with different types and severity of disability. Ann. Epidemiol. 24, 23-28 (2014).

9. Summers, J. et al. Self-injury in autism spectrum disorder and intellectual disability: exploring the role of reactivity to pain and sensory input. Brain Sci. 7, 140 (2017).

10. McTiernan, A., Leader, G., Healy, O. \& Mannion, A. Analysis of risk factors and early predictors of challenging behavior for children with autism spectrum disorder. Res. Autism Spectr. Disco. 5, 1215-1222 (2011).

11. Weiss, J. Self-injurious behaviours in autism: a literature review. J. Dev. Disabil. 9, 129-143 (2003).

12. Carroll, R., Metcalfe, C. \& Gunnell, D. Hospital management of self-harm patients and risk of repetition: systematic review and meta-analysis. J. Affect Disord. 168, 476-483 (2014).

13. Zhang J. Children with disabilities are more likely to be sexually abused. Disability China 40, 12 (2015).

14. Xing, Y., Qiao, Y., Duan, J. \& Bai, C. Prevalence of deliberate self-harm and its relation with suicidal behaviors among students in middle schools in Beijing. Chinese. J. Epidemiol. 36, 921-924 (2015).

15. Zhang, A. H., Tao, F. B. \& Su, P. Investigation on self-harm and the related factors in children and adolescents. Chin. J. Public Health 24, 1303-1305 (2008).

16. Classification and Grading Criteria of Disability. http://www.gov.cn/ztzl/gacjr/ content_459939.htm. Accessed 16 December 2017.

17. Zhu, H. P., Xia, X., Xiang, H. Y., Yu, C. H. \& Du, Y. K. Disability, home physical environment and non-fatal injuries among young children in China. PLOS ONE 7, e37766 (2012).

18. Zhu, H. et al. Sleep-related factors and work-related injuries among farmers in Heilongjiang Province, People's Republic of China. Int. J. Environ. Res. Public Health 11, 9446-9459 (2014).

19. Stallones, L., Beseler, C. \& Chen, P. Sleep patterns and risk of injury among adolescent farm residents. Am. J. Prev. Med. 30, 300-304 (2006).

20. De, L. D. \& Heller, T. S. Who are the kids who self-harm? An Australian self-report school survey. Med. J. Aust. 181, 140-144 (2004).

21. Hawton, K., Rodham, K., Evans, E. \& Weatherall, R. Deliberate self harm in adolescents: self report survey in schools in England. BMJ 325, 1207-1211 (2002).

22. Brunner, R. et al. Prevalence and psychological correlates of occasional and repetitive deliberate self-harm in adolescents. Arch. Pediatr. Adolesc. Med. 161, 641-649 (2007).

23. Baghdadli, A., Pascal, C., Grisi, S. \& Aussilloux, C. Risk factors for self-injurious behaviours among 222 young children with autistic disorders. J. Intellect. Disabil. Res. 47, 622-627 (2003).

24. Lewis, M. H. \& Bodfish, J. W. Repetitive behavior disorders in autism. Dev. Disabil. Res. Rev. 4, 80-89 (1998).

25. Oliver, C., Petty, J., Ruddick, L. \& Bacarese-Hamilton, M. The association between repetitive, self-injurious and aggressive behavior in children with severe intellectual disability. J. Autism Dev. Disord. 42, 910-919 (2012).

26. Nock, M. K. \& Prinstein, M. J. A functional approach to the assessment of selfmutilative behavior. J. Consult. Clin. Psychol. 72, 885-890 (2004).

27. Nock, M. K. Self-injury. Annu. Rev. Clin. Psychol. 6, 339-363 (2010).

28. Whitlock, J., Muehlenkamp, J. \& Eckenrode, J. Variation in nonsuicidal self-injury: identification and features of latent classes in a college population of emerging adults. J. Clin. Child Adolesc. Psychol. 37, 725-735 (2008).

29. Lundh, L. G., Bjärehed, J. \& Wångby-Lundh, M. Poor sleep as a risk factor for nonsuicidal self-injury in adolescent girls. J. Psychopathol. \& Behav. Assess. 35, 85-92 (2013).

30. Singareddy, R. et al. Subjective and objective sleep and self-harm behaviors in young children: a general population study. Psychiatry Res. 209, 549-553 (2013). 
31. Wong, M. M. \& Brower, K. J. The prospective relationship between sleep problems and suicidal behavior in the National Longitudinal Study of Adolescent Health. J. Psychiatr. Res. 46, 953-959 (2012).

32. Rossow, l. et al. Cross-national comparisons of the association between alcohol consumption and deliberate self-harm in adolescents. Suicide Life-Threat. Behav. 37, 605-615 (2007).

33. Hysing, M., Sivertsen, B., Stormark, K. M. \& O'Connor, R. C. Sleep problems and self-harm in adolescence. Br. J. Psychiatry J. Ment. Sci. 207, 306-312 (2015).

34. Hirshkowitz, M. et al. National Sleep Foundation's sleep time duration recommendations: methodology and results summary. Sleep. Health 1, 40-43 (2015).

35. ED, K. \& JJ, M. Self-injury: a research review for the practitioner. J. Clin. Psychol. 63, 1045-1056 (2007)
36. Nock, M. K., Prinstein, M. J. \& Sterba, S. K. Revealing the form and function of selfinjurious thoughts and behaviors: a real-time ecological assessment study among adolescents and young adults. J. Abnorm. Psychol. 118, 816-827 (2009).

37. Favazza, A. R. Bodies under siege: self-mutilation and body modification in culture and psychiatry. (Johns Hopkins University Press, Baltimore, MD, 1996).

38. Nock, M. K. Why do people hurt themselves? new insights into the nature and functions of self-injury. Curr. Dir. Psychol. Sci. 18, 78-83 (2009).

39. Achenbach, T. M., Mcconaughy, S. H. \& Howell, C. T. Child/adolescent behavioral and emotional problems: implications of cross-informant correlations for situational specificity. Psychol. Bull. 101, 213-232 (1987).

40. Jozefiak, T., Larsson, B., Wichstrøm, L., Mattejat, F. \& Ravens-Sieberer, U. Quality of Life as reported by school children and their parents: a cross-sectional survey. Health Qual. Life Outcomes 6, 34 (2008). 